\title{
Transmigrant and immigrant preschool visual response to intergenerational multimodal storytelling
}

\begin{abstract}
Newly arrived (refugees, migrants, transmigrants, immigrants) children require a shift in intergenerational storytelling. Intergenerational storytelling enables culturally and linguistically diverse emergent learners exposure to not only language but socio-cultural knowledge, values and practices. This study examines the intergenerational storytelling and art session held at a co-joined pre-school and elderly care home. There were 15 pre-school children aged 4-6, half of whom were newly arrived in Finland, and 4 Finnish elder storytellers. The theme of the project was to utilize everyday socio-cultural practices. The study used Pink's visual semiotic and Kress' multimodality for analysis. The research investigated two questions: 1) To what extent can intergenerational multimodal storytelling benefit transmigrant, immigrant community engagement and identity? 2) In a globalized world, how do children's relationships with multimodalities create learning (language, socio-cultural practices)? Data was collected from qualitative pre - and post-session discussions from the six storytelling sessions, video recordings made by the participants, and multimodal artwork created by the children after each storytelling session. The results revealed transmigrant children engaged with components of stories that connected to their residency situation. Additionally, children represented themselves in the art as response to multimodal storytelling sessions. Interactive storytelling was effective means for socio-cultural interaction between pre-school children and elderly storytellers/people.
\end{abstract}

Keywords: intergenerational storytelling, arts-based literacy, visual discourse, transmigrant

\section{Introduction}

Transmigrant pre-school children (4-6) face challenges in their life experience as they adjust and integrate into their new school and community (Clinton, 2015). The challenges they face are not just learning a new language. 
There are intersecting social, psychological barriers that interfere in emergent language and literacy practices such as a lack of socialization coupled with a lack of understanding of everyday socio-cultural practices of the new country of residency (Rucpic, 2018). For later academic success in learning, emergent learners (under seven years of age) need increased exposure to context-embedded vocabulary to better facilitate knowledge comprehension (Heath, 1983). As prior research indicates, storytelling practices provides an increase in exposure to vocabulary situated in daily socio-cultural context and practices (Luo, and Tamis-LeMonda, 2017). This is the rationale for the project choosing to implement an intergenerational, multimodal storytelling program for mixed background pre-school children (transmigrant, immigrant, and local Finnish). The informal learning program was based on everyday topics such as childhood, clothing, arts and crafts, sports, games, and food rather than from storybooks (Flewitt, 2013) All of the oral stories covered everyday cultural knowledge specific to Finland, thus, increasing emergent language learners' social context-bound vocabulary knowledge (Dyson, 2016).

The paper highlights a program instituted in an informal learning environment designed to create engagement and build bridges between elder storytellers and pre-school immigrant/transmigrant and local children. The caring practices, to ensure community building was weekly multimodal intergenerational storytelling sessions, followed by the children art-based creative reflections of responding to the storytelling content. Intergenerational storytelling has occurred since the beginning of time (Heydon, 2012). Research reveals that intergenerational multimodal storytelling highlights children's connections to past practices, memories and symbols as story represents memories and cultural identity (Wessel-Powell, Kargin and Wohlwend, 2016). However, few studies have examined multimodal oral storytelling and children's visual art creations as reciprocal responses investigating children's knowledge learnt from these multimodal storytelling interactions. A final objective of the program process was to strengthen the relationship between generations while providing a space for immigrant, transmigrant, and local children to have a voice. This occurred through arts-based creation by the children to the multimodal storytelling.

Therefore, the aim of the project is two-fold. The first is to provide opportunities for the Finnish elder and transmigrant, immigrant, and local children to experience the similarities in cultural heritage practices (food, culture) that multimodal storytelling can teach them. The second aim was to investigate 
how these children learn, intersecting knowledge of everyday, cultural, and historical language and practices through art-based communications. Additionally, to investigate to what degree does this allows them to reconceptualise and own the knowledge transmitted from the intergenerational oral stories. The study investigated: To what extent can intergenerational multimodal storytelling benefit transmigrant, immigrant community engagement and identity? In a globalized world, how children's relationships with multimodalities create learning (language, socio-cultural practices)?

\section{Culturally and linguistically diverse learners}

Young culturally and linguistically diverse (CLD) learners and their families (transmigrant and immigrant) may encounter challenges while settling into their new educational environment. Emergent learners whose home culture differs from mainstream culture (Clinton, 2015). These learners come from a wide range of backgrounds. Therefore, it is not just the language, but emergent culturally diverse learners need socio-culturally embedded practices intersecting with language. Emergent language development should include the opportunity to hear the basic sounds of language, relate these sounds to meanings, and respond verbally (Clinton, 2015). Using voice, gestures and multimodality enables transmigrant and L2 learners to overcome learning gaps (Kress and Jewitt, 2003). This includes expanding vocabulary through multimodal (objects, artefacts photos) to raise comprehension. Providing ample generous opportunities for exposure to oral language throughout the day (one-to-one, pairs, small groups, large groups). Developmental differences exist between learners regardless of their cultural origin. A wide variety and multimodality of language experiences embedded in intergenerational storytelling have a significant impact on the learner's ability to make sense of new learning regardless of cultural origin (Patino-Santos and Relaño Pastor, 2018). As the research indicates emergent learners (immigrant, migrant and local) requires various means of language co-production such as paralinguistic, socio-cultural, interactional, and most importantly multimodal (Dyson, 2016).

\section{Multimodality}

This project expands from Narey (2009) previous research, which examined how children develop multimodal narratives through the construction of 
quilt squares to represent who they were and what was important in their world. The present study investigated the alternative ways children communicate and learn everyday social integration practices through visual artsbased responses to multimodal intergenerational storytelling (Rupcic, 2018). Narey (2009) advocated for using the arts as a process that develops and extends language, literacy, and meaning-making. Viewing the arts as a visual language and literacy offer another lens on viewing young children's meaning-making and on how they make their graphic thought visible through visual narratives" (p340).

Revealing their identity texts (Cummins, 2004) through multimodal engagement reflects the significance of being able to understand, communicate, and think in alternative ways and illuminates how children navigate the relational landscape of their visual literacy narratives (p341)". Also contributing to this developing socio-cultural learning were weekly opportunities to tell elder stories, respond to these stories, and listen to each other. Understanding the socio-cultural significance of children's experiences enriches the dimension of learning interactions (Luo and Tamis-LeMonda, 2017). Honouring personal histories through intergenerational visual discourse provides the possibilities of co-creating an environment that values the building of community.

\section{Visual representations}

Storytelling is a critical social mechanism for the intergenerational transmission of cultural values, knowledge, and practices (Brown, 2013). Storytelling is not just the linguistic and text components but with this generation encompasses a wider array of modalities (art, sounds, objects, and interaction). The visual discourse of children and their families not only provides a socially constructed lens of understanding but also enables reflection and potential for transforming learning practices" (Cummins, 2004 p341). Understanding that visual representation is presented in the art and additionally that reconceptualizes what the children believe to be relevant from the story is important for multicultural globalized identities. This expands not only children's ability to communicate and represent learning and identity. Their artwork becomes visual discourse representing their response to multimodal storytelling (Porte, 2000; Wessel-Powell, Kargin and Wohlwend, 2016). The children communicated, through multimodal visual discourse, their reinterpretation of what the story meant to them. Therefore, children can find their 
voice by visualizing what was significant to them. This manifested in selfconfidence to represent ideas pictorially and to express verbally.

\section{Methods}

This article stems from a larger two-year study called Building Bridges (2018-2020) involving newly arrived and settled groups (preschoolers, children, young people, community workers, and elders). The research was conducted at a twinned preschool and aged care home. We recruited elder volunteers from those who either lived in the care home or lived by themselves nearby: one man and three women in their late 60s to mid-70s. Additionally, there were 15 multicultural preschool children (ages 4 to 6 years old) participants. The children, whom all came from the adjoining preschool, formed two groups: eight children aged 5-6, and seven children aged 4-5. All participants both elder and children were pseudonymized. All participants (teachers, elder care staff, and children), plus the parents of the preschool children and the school staff, gave their informed consent; one child asked that their face not be video-recorded, and this request was met. Additionally, one elder resident asked not to be videotaped or photographed as she had suffered a stroke causing paralysis on one side of her face. Any children who did not wish to participate remained in daycare. In addition, the children and their parents were asked if photos and videos of their artwork could be displayed during conferences and as well could be included in articles (with names removed). Utilizing the art as data was agreed upon by all parties. Additionally, after initial data analysis the researchers contacted the parents and discussed the findings to confirm and clarify any inferences made about the images. It should be highlighted the art as stipulated in the research statement, would be exhibited both at a multicultural center and the central library for weeks. The study complied with GDPR rules concerning privacy protection, data management, right to withdraw, data storage, processing, and transportation.

Five weekly sessions over a three-month period, that culminated in two weeks of exhibitions of the children's artwork at a multicultural centre and the central library. After each story session, the children created artwork to respond to the story. Each week the artwork was in different forms and modalities (photos, drawings, colouring, finger painting, collage). This was to allow the children different visual modalities to express themselves. Initially, we began with allowing the children to just draw using crayons and colour pencils. Slowly over time, we incorporated other visual artistic means. The 
art was finished in the adjacent room of the eldercare home. The data consisted of participant - and researcher-produced video recordings of the six oral storytelling sessions, observational field notes, multimodal artefacts, and qualitative pre-and post-session interviews. There were two sets of video recordings, one by the researchers and one by participants.

The data analysis of the artwork and stories assessed the story themes compared with visual images in the children's artwork. The analysis utilized Kress (2010) multimodal mediation of knowledge and Pink (2008) visual semiotics. The research team, elder care, and early childhood staff as well as the elder storytellers confirmed and clarified with the children the meanings of the visual representation. The categories of analysis included colour, layout, visual representation connecting to socio-cultural practices, multimodal objects, and participatory actions. Additionally, past, present, and future identity was assessed in the artwork.

\section{Findings}

The findings discovered moments of identity representation, connecting to socio-culture, context vocabulary and prior historical cultural practices. An example that illustrates this was when Anja shared her childhood memories in a small countryside parish. She also revealed that a famous Finnish clown, Pelle Hermanni, used to live in the same house as her grandmother. This interested the children. This story initiated their engagement. They asked about who lived in Jyvaskyla back then and what it was like. Jorma had many stories and many photographs. These helped capture the children's attention and they asked many questions. Leila described being a young child in the countryside during the war. She narrated that there was no road to her home, nor did her home have electricity of any other modern-day conveniences. The family had to keep the house dark during the night due to night bombings. The boys were interested in asking questions about bombings and war. They were especially interested in the planes.

The children's art displayed visual discourse representing what moments connected to them the most. For each child it was different. Art reflected personal connections to the story. For example, the boys highlighted the aeroplanes in WW2 of the childhood stories as their grandparents' spoke of similar stories. Boys connected to action, planes items and the girls highlighted the people and surrounds. For example, in the topic of childhood, many of the children drew pictures of houses as a reflection of childhood 
and Jyvaskyla. While most of the stories described the hardships of past life in Finland, the children connected with the notion of family and home. They also integrated the idea that the elders, when they were children, lived through dangerous times (See figure 1-3 below).

Figure 1. Planes WW2

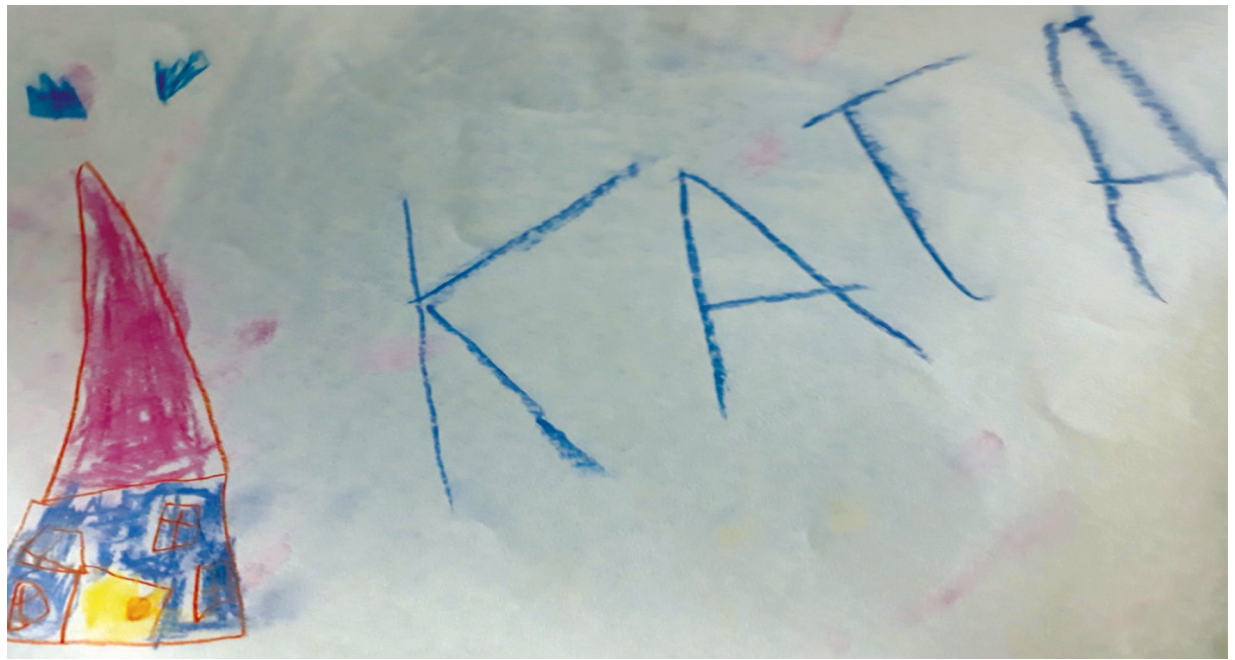

Figure 2. Nature no electricity

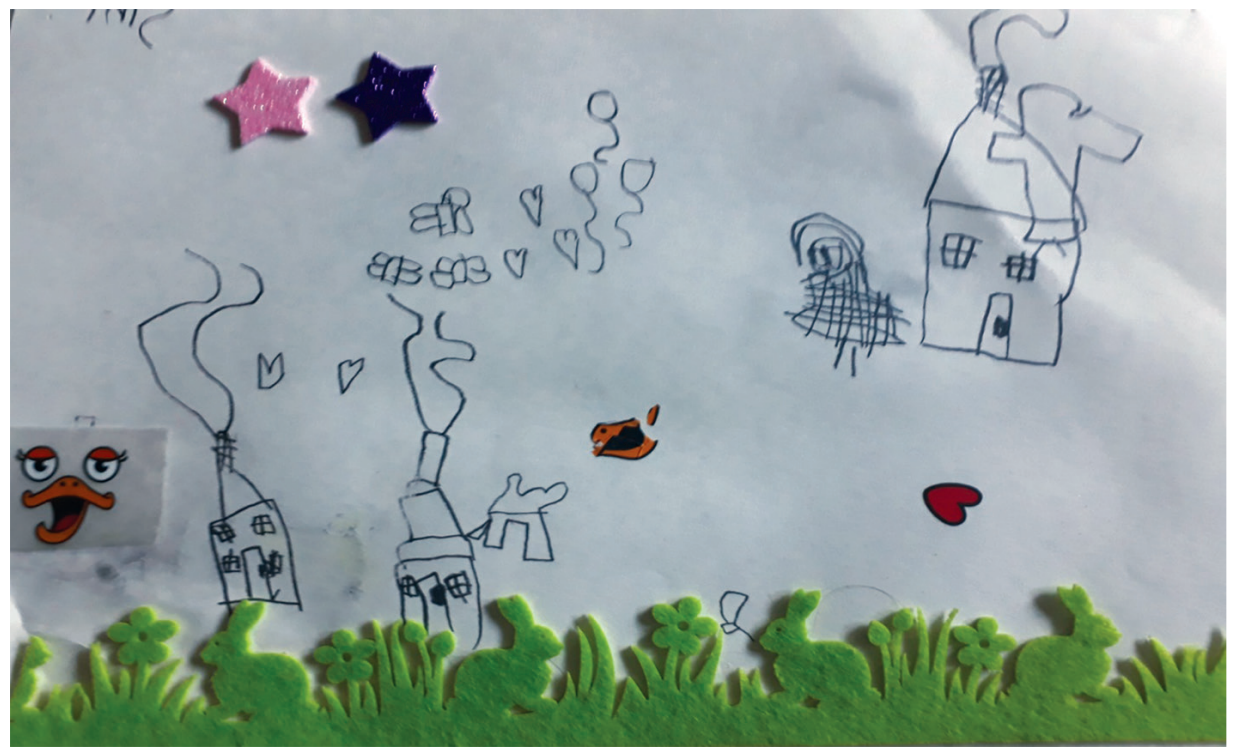


Figure 3. Black sun WW2

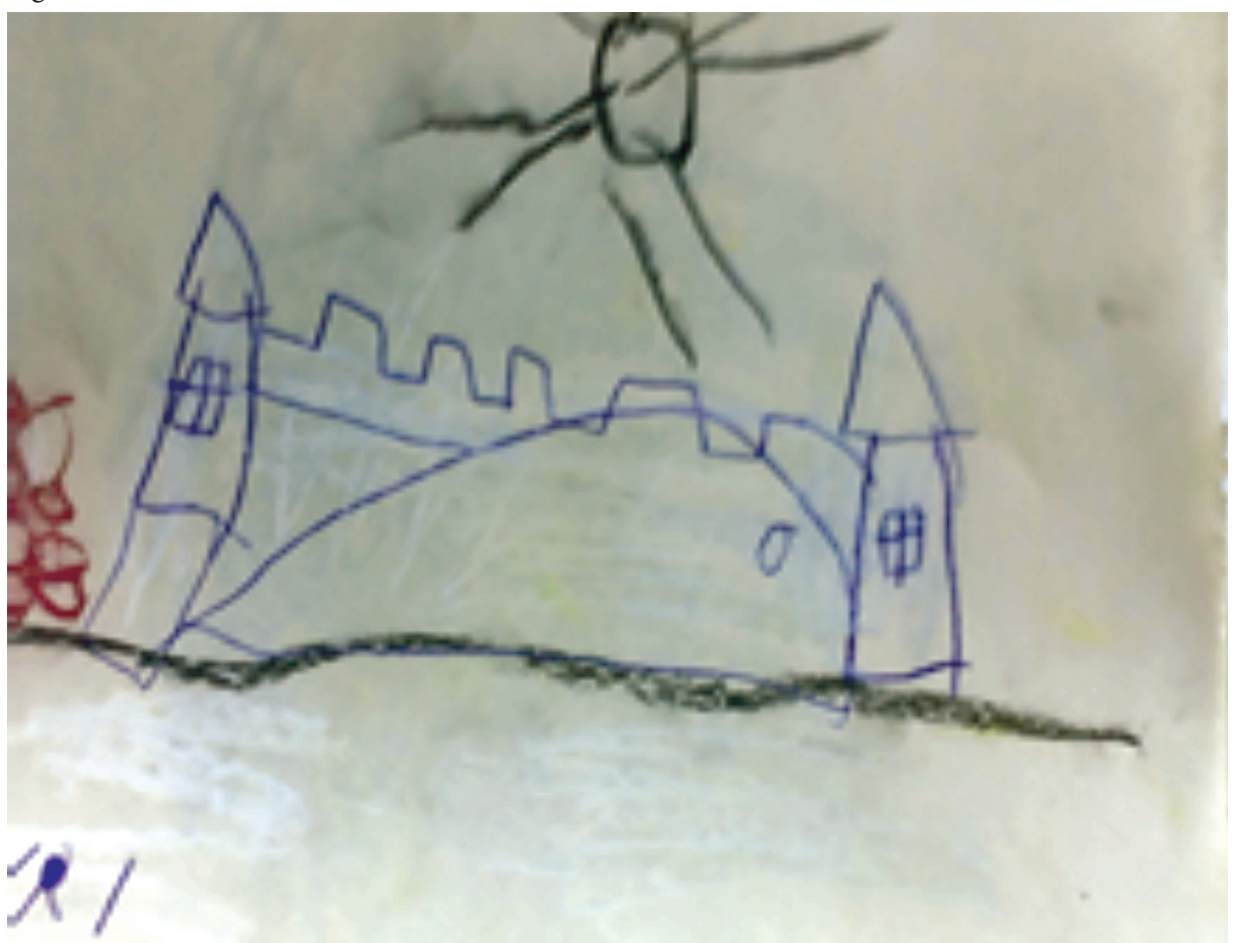

\section{Findings - representation}

In the clothing session the children learnt about the older fashion. This was interactive as the elder storytellers brought in examples of clothing not just pictures. Anja had a lot to talk and show about the clothing of yesteryear. She showed the kids how the different aprons were put on for baking. The children tried on some of the hats and clothing. The listeners wondered how there were no paper tissues before but cotton handkerchiefs. During the clothing session, one transmigrant girl chose to utilize a Disney princess of colour. There were 'white' examples in the comic she chooses to use the Princess of colour. She said the girl in the picture looked more like her, white darker-skin and dark hair. 
Figure 4. Representing Self

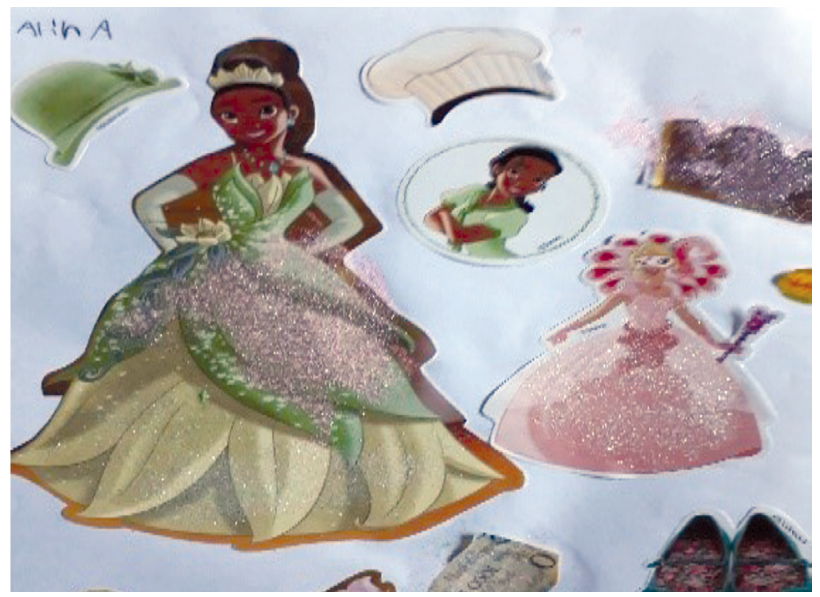

Additionally, the princess character she chose had a fancy long dress (ball gown). She said she thought that it represented what she thought Finnish grandparents might have worn in the past. Several children, when asked about their artwork, stated that they thought the vintage (old) clothes sounded like they would be more elegant. Hence, the use of glittery stickers to represent this feeling.

Figure 5. Beauty of old clothes

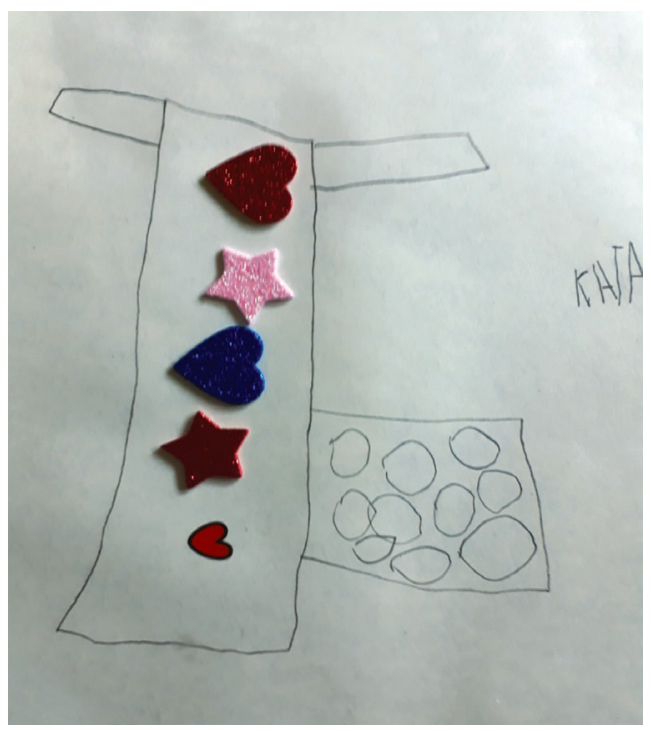


Certain images reflect objects the children focused on their art highlighted the knowledge taken from the stories, not the main action of the story. The art also displayed moral values such as beauty, heroism, strength in the pictures and with their choices from the magazines (using superheroes). Kids incorporated their lives into the arts. They utilized syncretic globalized images ex batman going fishing during the sports session. An example of syncretism was many of the pictures used both traditional Finnish comic characters (Moomin) alongside Disney or Minecraft (gaming). The choices reflected the transcultural identity of their lived in Finland. Additionally, the $3 \mathrm{D}$ sports visually represented the movement in sports including animation action characters such as Batman etc. The storytellers brought in fishing, skiing, and hiking gear for the children to see. They also told stories about going up to Lapland and falling through the ice when Nordic skiing on a lake. The children saw pictures of having to dry clothing on an open fire.

Figure 6. Globalization of sports

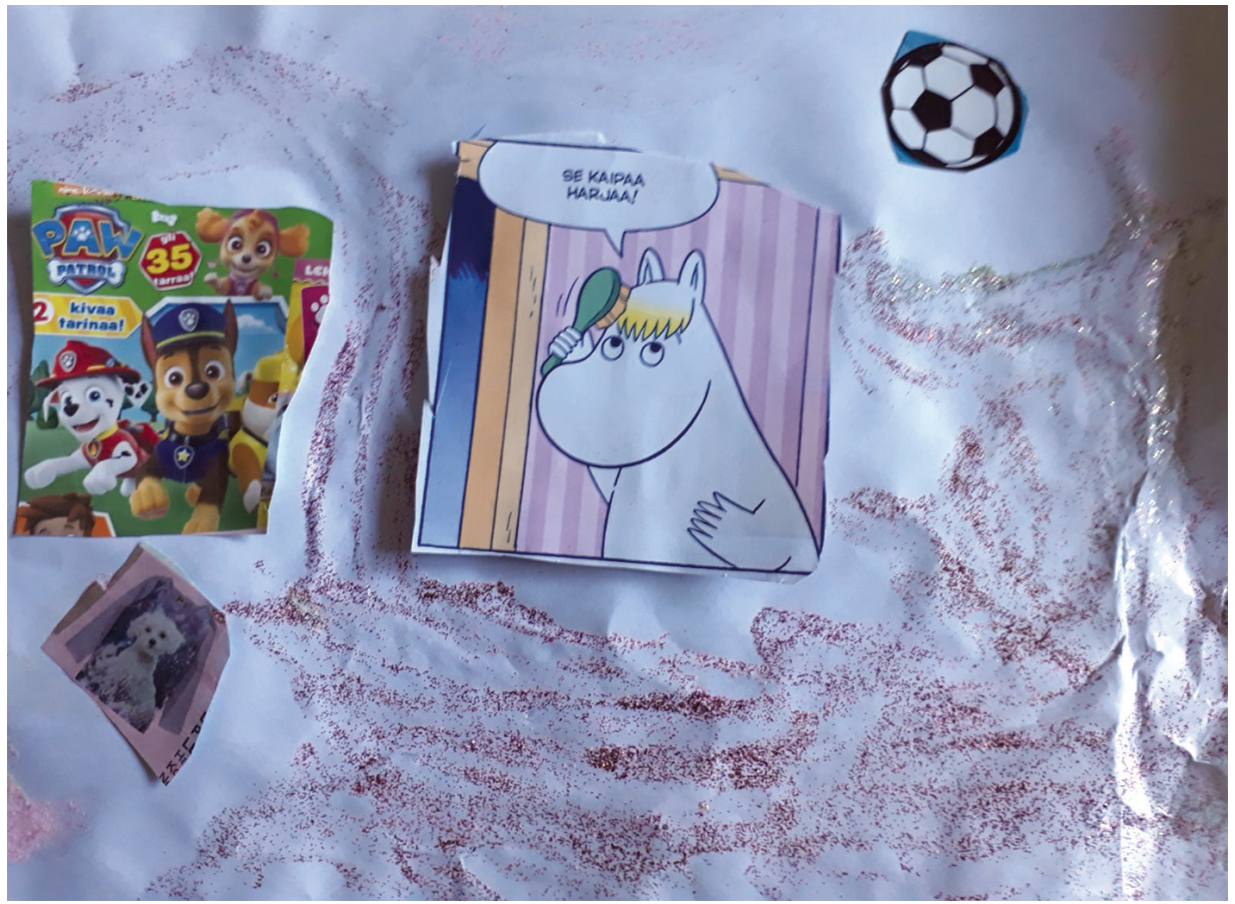


Figure 7. Movement in sports

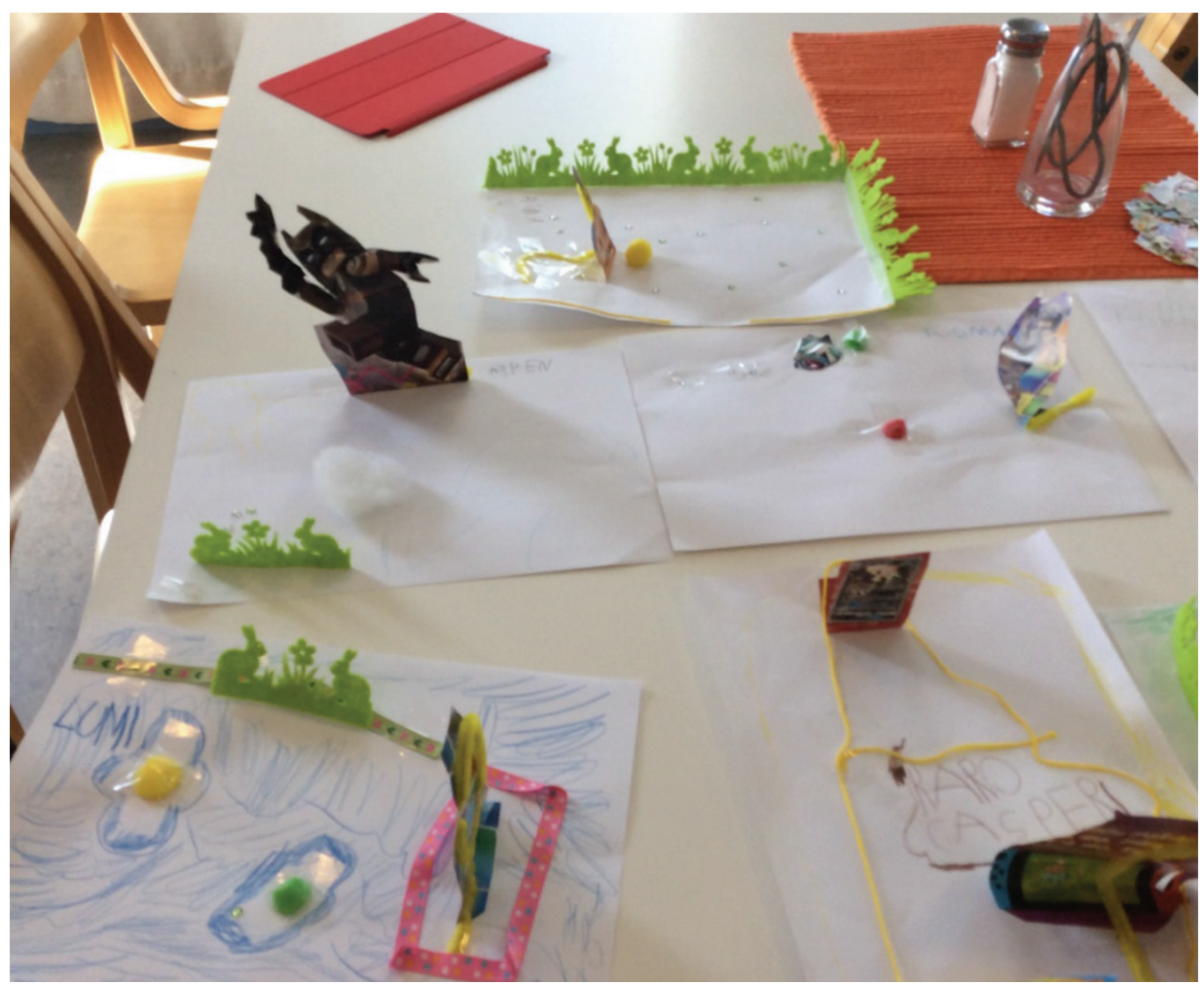

The visual representation in the children's' art reflected the interactive nature of the theme and the storytelling. The multimodal nature of the storytelling enabled the children played games such as hide the key. They learnt the song for picking a player. They also played the old Finnish 10 stick game. All these games allowed them to learn how children played in the past without any computers. It expanded their socio-cultural language and knowledge of Finnish cultural practices. The storytellers also played with old dolls and paper games. The children played hide the object games. This was very successful in engaging them to listen. The children asked many questions such as "How did you play with these?" "Whom did you play with?" "Where these expensive and popular?" The interactive nature of the game was represented in the 3D artwork below 
Figure 8. Interactive storytelling

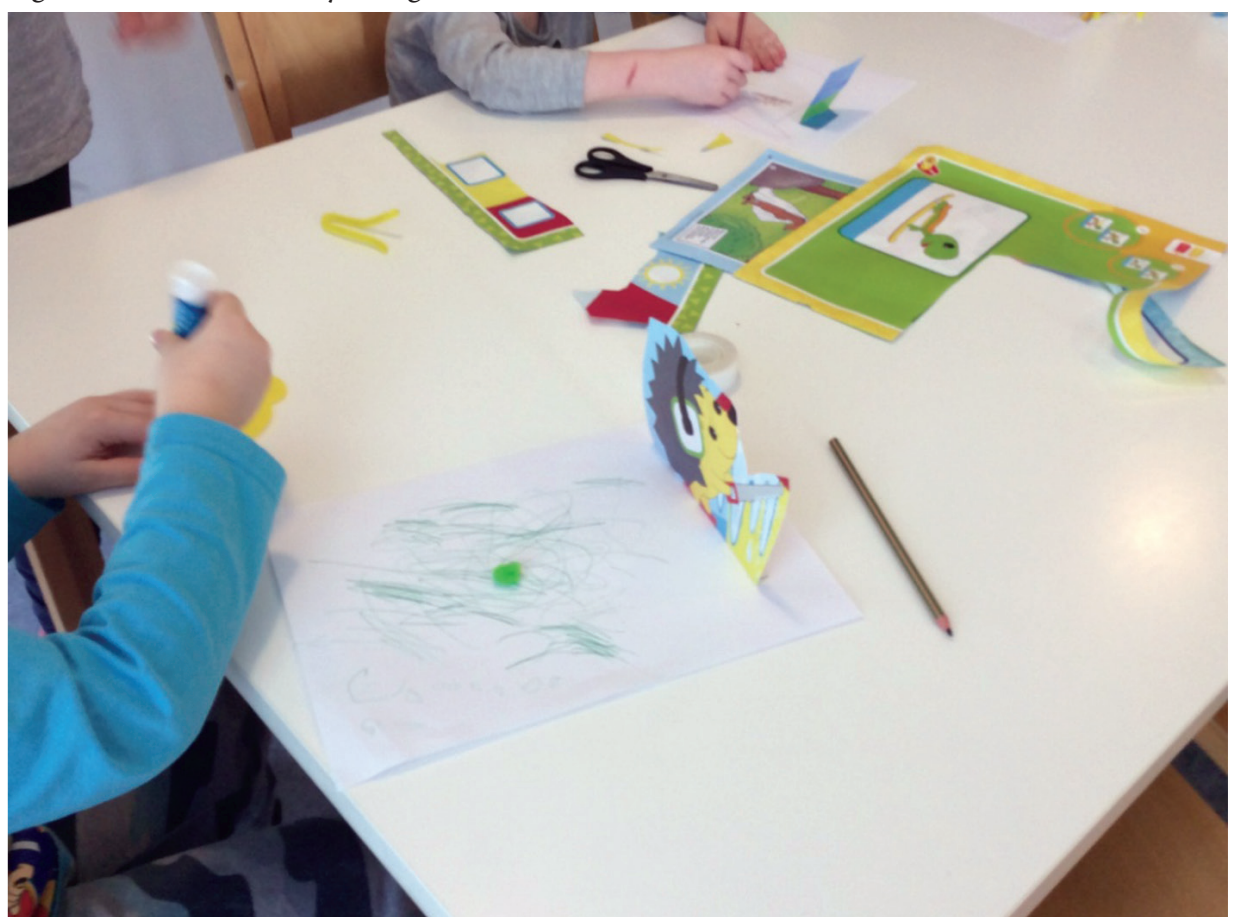

Multimodality in art allowed them to reconceptualize the stories from their perspective. They did not conceive the literal truth of the visual image but utilized the image or something they saw in the image to project what they wanted. Over the weeks, the children explained their pictures as being about the simple and emotional aspects of the stories. For them, this was represented through the visual colour and look of the pictures.

\section{Conclusions}

The study illustrated children's responses to multimodal storytelling through the discourse of visual and art-based literacy. The findings answered, to what extent can intergenerational multimodal storytelling benefit transmigrant, immigrant community engagement and identity? There were three areas of interest regarding these responses to multimodal intergenerational storytelling. The first, notion was that a response to the storytelling, children often incorporated their lives into the arts including local and global perspectives. 
A second finding revealed that the children's art displayed visual discourse representing what moments connected to them the most. The final finding was the interactive aspects of multimodality intergenerational storytelling. Through allowing children to respond to the stories by utilizing multimodality in the art provided them with agency and space to reconceptualize the stories from their perspective. Furthermore, the findings illustrated that in a globalized world, children's relationships with multimodalities create learning (language, socio-cultural practices)? The focus of the art highlighted socio-cultural practices, fishing, sports, and old clothing that provided new vocabulary and knowledge for the children. Therefore, intergenerational, multimodal storytelling often serves to transmit cultural values and family history (Luo and Tamis-LeMonda, 2017) and done as a multicultural community strengthens civic engagement. The children learnt about the past historical lives of the elder storytelling. Their art displayed taking moments from the stories and reconeptualizing them with modern visual literacy. Additionally, through providing opportunities for visual discourse this project over time hoped to connect other groups (immigrant with elder and children) with the hope of providing both local and newly arrived through storytelling.

The limitation of the study is the small group of participants. However, the videos during the multimodal intergenerational storytelling and the following art creation illustrates a need for future investigation. Oral history enables the reconstruction of shared memory through experiences. As the storytelling becomes multimodal and interactive, the visual discourse in the children's artwork reflected this. It went from literal drawings of events to representations of how the events connected to the children's present identity. The drawings became shared representational discourse of the process rather than just the story. These were children not familiar with Finnish historical culture. However, through multimodal intergenerational storytelling they became engaged. Moreover, their artwork illustrated the vocabulary and themes that the children engaged in.

Future research must investigate how with linguistic proficiency transmigrant children can learn, share knowledge and interact multimodally with story creation. As well, this process captured relevant significance for the children the greater their involvement because in the discourse process. As such, we argue we need greater interactional multimodal opportunities in intergenerational storytelling. This benefits identity and well-being of all the participants. Therefore, allowing the children through art-based literacy to respond to the stories enables transmigrant and immigrant children a space 
to learn about socio-cultural practices of their present residency. Additionally, it enables emergent learners a space to communicate and express themselves.

\section{Bibliography}

Brown, L. 2013. Storytelling and ecological management: understanding kinship and complexity. Available from: www.jsedimensions.org. Accessed 6 July 2016.

Clinton, J. 2015. Teaching strategies that address trauma and resilience. LearnTeachLead video. Cole, R.W. (2008). Educating everybody's children: Diverse teaching strategies for diverse learners (Revised and Expanded 2nd Ed.), Alexandria, VA: ASCD.

Dyson, A.H. ed 2016. Child Cultures, Schooling, and Literacy: Global Perspectives on Composing Unique Lives. London and New York: Routledge. Flewitt, R. 2013. Multimodal perspectives on early childhood literacies. In: Larson, J. and Marsh, J. eds. The Sage Handbook of Early Childhood Literacy. Los Angeles, CA: Sage, pp. 295-310.

Heath, S. 1983. Ways with Words: Language, Life and Work in Communities and Classrooms. Cambridge: Cambridge University Press.

Heydon, R.M. 2012. Multimodal communication and identities options in an intergenerational art class. Journal of Early Childhood Research. 10 (1), pp. 51-69.

Kenner, C., Ruby, M., Jessel, J., Gregory, E. and Arju, T. 2007. Intergenerational learning between children and grandparents in East London. Journal of Early Childhood Research. 5 (3), pp. 219-243.

Kress, G. and Jewitt, C. 2003. Introduction. In: Jewitt. C. and Kress, G. eds. Multimodal Literacy. New York: Peter Lang, pp. 1-18.

Luo, R. and Tamis-LeMonda, C.S. 2017. Preschool book-sharing and oral storytelling experiences in ethnically diverse, low-income families. Early Child Development and Care. 189 (2), pp. 1-18.

Narey, M. ed. 2009. Making Meaning: Arts-based Early Childhood Education Constructing Multimodal Perspectives of Language, Literacy, and Learning through. New York: Springer-Verlag USA.

Patino-Santos, A. and Relaño Pastor, A.M. 2018. Storytelling in globalized spaces: a linguistic ethnographic perspective. International Journal of the Sociology of Language. 250, pp. 1-10.

Pink, S. 2008. Mobilising visual ethnography: Making routes, making place 
and making images. Forum Qualitative Sozialforschung/Forum: Qualitative Social Research. 9 (3), pp. 1-17.

Porte, A.M.L. 2000. Oral history as intergenerational dialogue in art education. Art Education. 53 (4), pp. 39-44.

Rupčić, N. 2018. Intergenerational learning and knowledge transfer: Challenges and opportunities. The Learning Organization. 25 (2), pp. 135-142. Wessel-Powell, C., Kargin, T. and Wohlwend, K.E. 2016. Enriching and assessing young children's multimodal storytelling. The Reading Teacher. 70 (2), pp. 167-178. 